\title{
Mapping the spatial distribution of the biomass and filter-feeding effect of invasive dreissenid mussels on the winter-spring phytoplankton bloom in Lake Michigan
}

\author{
MARK D. ROWE*, , DANIEL R. OBENOUR ${ }^{*} \S$, THOMAS F. NALEPA*, HENRY A. VANDERPLOEG*, \\ FOAD YOUSEF* AND W. CHARLES KERFOOT ${ }^{\Uparrow}$ \\ *NOAA Great Lakes Environmental Research Laboratory, Ann Arbor, MI, U.S.A. \\ ${ }^{\dagger}$ Cooperative Institute for Limnology and Oceanography, University of Michigan, Ann Arbor, MI, U.S.A. \\ ${ }^{\ddagger}$ Department of Civil, Construction and Environmental Engineering, North Carolina State University, Raleigh, NC, U.S.A. \\ ${ }^{\S}$ Water Center, Graham Institute of Sustainability, University of Michigan, Ann Arbor, MI, U.S.A. \\ "Department of Biological Sciences, Michigan Technological University, Houghton, MI, U.S.A.
}

\section{SUMMARY}

1. The effects of the invasive bivalves Dreissena polymorpha (zebra mussel) and Dreissena rostriformis bugensis (quagga mussel) on aquatic ecosystems, including Lake Michigan, are a topic of current interest to scientists and resource managers. We hypothesised that the winter-spring phytoplankton bloom in Lake Michigan is reduced at locations where the fraction of the water column cleared per day by Dreissena filter feeding approached the net growth rate of phytoplankton, when the water column was not stratified. To test this hypothesis, we compared the spatial distribution of Dreissena filter-feeding intensity (determined from geostatistical modelling) to the spatial distribution of chlorophyll (determined from satellite remote sensing).

2. To map the spatial distribution of Dreissena biomass and filter-feeding intensity, we developed a geostatistical model based on point observations of mussel biomass measured in Lake Michigan in 1994/1995, 2000, 2005 and 2010. The model provided fine-scale estimates of the spatial distribution of biomass for the survey years and provided estimates, with their uncertainty, of total biomass lakewide and within subregions. The approach outlined could be applied more generally to map the distribution of benthic biota in lakes from point observations.

3. Total biomass of Dreissena in Lake Michigan, estimated from the geostatistical model, increased significantly over each five-year period. The total biomass in units of $10^{6} \mathrm{~kg}$ ash-free dry mass (AFDM) (with 90\% confidence interval) was 6 (4-8) in 1994/1995, 18 (14-23) in 2000, 408 (338-485) in 2005 and 610 (547-680) in 2010. From 1994/1995 to 2005, increases were observed in all regions of the lake (northern, central and southern) and in all depth zones ( $<30,30-50,50-90$ and $>90)$. However, from 2005 to 2010, for depths of $<50 \mathrm{~m}$, biomass declined in the northern region, remained constant in the central region and increased in the southern region; biomass continued to increase in all three lake regions for depths $>50 \mathrm{~m}$.

4. The filter-feeding intensity of Dreissena exceeded the benchmark spring phytoplankton growth rate of 0.06 day $^{-1}$ in 2005 for depths $<50 \mathrm{~m}$ (lakewide). In 2010, the filter-feeding impact exceeded 0.06 day $^{-1}$ within depths $<90 \mathrm{~m}$ (lakewide), which greatly increased the spatial area affected relative to 2005. A regression analysis indicated a significant relationship between the reduction in satellitederived chlorophyll concentration (pre-D. r. bugensis period to post-D. r. bugensis period) and spatially co-located filter-feeding intensity (fraction of water column cleared per day) during periods when the water column was not stratified (December to April).

Keywords: benthos, GIS, invasive species, invertebrates, lakes, modelling, physical environment, population, statistics

Correspondence: Mark D. Rowe, NOAA GLERL, 4840 S. State Road, Ann Arbor, MI 48108, U.S.A. E-mail: mdrowe@mtu.edu 


\section{Introduction}

The dreissenid mussels, Dreissena polymorpha (zebra mussel) and Dreissena rostriformis bugensis (quagga mussel), are prolific invaders of aquatic ecosystems. Dreissena originated in the Ponto Caspian region and spread to many aquatic systems in Europe in the 19th and 20th centuries (Vanderploeg et al., 2002; Karatayev, Burlakova \& Padilla, 2014). The larval mussels were carried to North America in ship ballast water (Brown \& Stepien, 2010), and adults were first reported in the Laurentian Great Lakes in 1988, subsequently spreading through the Mississippi River system and to lakes and reservoirs in western North America (Benson, 2014). The spread of Dreissena is facilitated by their pelagic larval stage and the ability of adults to attach to hard substrata, including boats and ships, traits that are lacking in most freshwater bivalves native to North America (Vanderploeg et al., 2002; Karatayev et al., 2014).

Dreissena polymorpha and D. r. bugensis share many similarities; however, D. r. bugensis is much better adapted to deep water. Karatayev et al. (2011) reviewed the course of invasion of D. polymorpha and D. r. bugensis across waterbodies in Europe and North America and found that the two species often coexist in shallow systems although, in deep lakes, D. r. bugensis typically displaces $D$. polymorpha to become the dominant species within 10 year after it invades. Most of Lake Michigan is sufficiently deep ( $75 \%$ of the lake area is $\geq 30 \mathrm{~m}$ ) to provide an advantage to D. r. bugensis over D. polymorpha. Consistent with the pattern observed in other systems, D. r. bugensis has displaced D. polymorpha in Lake Michigan: D. polymorpha was alone in 1994/1995, D. r. bugensis began to invade northern Lake Michigan in 2000 (first found in 1997; Nalepa et al., 2001), and total Dreissena biomass consisted almost exclusively of D. r. bugensis in 2005 (Nalepa, Fanslow \& Pothoven, 2010) and 2010 (Fig. 1: Nalepa et al., 2014).

As an ecosystem engineer, Dreissena modifies aquatic systems in several ways, having substantial ecological (Karatayev, Burlakova \& Padilla, 2002; Vanderploeg et al., 2002) and economic effects (Connelly et al., 2007). Dreissena alters benthic substrata by creating aggregates of living mussels ('druses') and deposits of shells. Dreissena may create additional food and habitat for invertebrates in the littoral zone, but quagga mussels in deep water may outcompete other invertebrates, decreasing their diversity and density (Vanderploeg et al., 2002; Karatayev et al., 2014). The system-wide effect of Dreissena in most waterbodies is to reduce phytoplankton abundance (chlorophyll concentration) through the

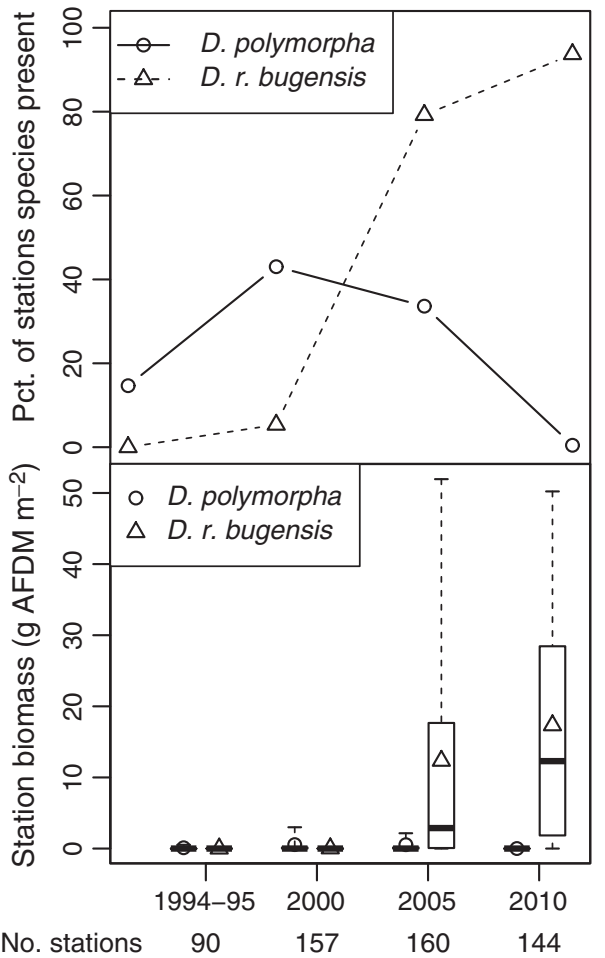

Fig. 1 Summary of the Dreissena survey data (Ponar grab samples, Nalepa et al., 2014), showing the displacement of Dreissena polymorpha by D. r. bugensis over the study period. The top panel shows the percentage of stations at which each species was detected. The bottom panel shows boxplots of biomass at the sampling stations. Boxplots indicate the 5th, 25th, 50th, 75th and 95th percentiles of the observations, and the mean is indicated by a symbol. The number of stations sampled in each period is given below the plot.

direct effect of filter feeding (Karatayev et al., 2014; and works cited therein), although there are some mechanisms through which Dreissena can increase primary production under certain circumstances. For instance, Dreissena increases water clarity through filter feeding and regenerates dissolved nutrients, which can stimulate growth of attached algae (e.g. Cladophora) and macrophytes to nuisance values (Vanderploeg et al., 2002; Hecky et al., 2004; Auer et al., 2010). Dreissena may also promote the dominance of cyanobacterial blooms through selective feeding and alteration of the phosphorus cycle (Vanderploeg et al., 2001; Obenour et al., 2014; Steffen et al., 2014), although such blooms are not presently an issue in the oligotrophic main body of Lake Michigan. In addition, Dreissena alters the abundance and distribution of fish and wildlife through effects on benthic habitat and prey species distribution (e.g. Schummer, Petrie \& Bailey, 2008). Because of the diverse effects of Dreissena on invaded systems, detailed distribution maps and estimates of their lakewide biomass are useful to ecologists and resource managers in 
measuring and understanding the changes associated with invasion.

To map spatial distribution, or to estimate an aggregated total over given spatial areas, it is necessary to predict abundance for locations where observations are not made. Surveys of the benthos, including dreissenids, usually consist of a limited array of point observations, with the number of points being limited by the considerable cost of data collection and sample processing. Nalepa, Fanslow \& Lang (2009) reported Dreissena numerical density and biomass in Lake Michigan, derived from Ponar grab sample surveys conducted in 1994/1995, 2000 and 2005; they produced maps of the spatial distribution of Dreissena numerical density using natural neighbour spatial interpolation (Sibson, 1981), and acknowledged the tendency of this method to overestimate Dreissena density in deep water, where mussel densities were expected to be low. Further, Nalepa et al. (2009) estimated lakewide biomass by taking the areaweighted mean of point observations within four broadly defined, bathymetric depth intervals $(\leq 30,30-50$, 50-90 and $>90 \mathrm{~m}$ ), but did not account for spatial trends within the depth intervals. Bathymetric depth is an important predictor for the distribution of benthic biota. For example, Auer et al. (2013) reviewed 19 studies that found maxima in the abundance of benthic animals (primarily Diporeia spp.) within the Great Lakes at depths between c. 30 and $50 \mathrm{~m}$. Auer et al. (2013) collected Ponar grab samples of Diporeia in Lake Superior in cross-isobath transects and identified a depth range (or sediment grain size range) of high abundance ( $>95$ th percentile of profundal abundance); lakewide spatial distribution of abundance was then estimated based upon bathymetry and grain size maps. The geostatistical modelling approach described here offers advantages over previous methods of spatial prediction or interpolation applied to benthos in the Great Lakes: (i) covariates such as bathymetry are readily incorporated, and (ii) predictive uncertainty is readily quantified.

Here, we test the hypothesis that the winter-spring phytoplankton bloom was reduced in locations where Dreissena filter-feeding intensity approached or exceeded the net growth rate of phytoplankton. Prior to establishment of a large population of D. r. bugensis in Lake Michigan, there was a winter-spring phytoplankton bloom, with chlorophyll concentration gradually increasing from February until the onset of stratification in late April-May (Fig. 2; data source: Yousef et al., 2014). The disappearance of the winter-spring phytoplankton bloom in the southern basin of Lake Michigan after establishment of D. r. bugensis has been documented by several

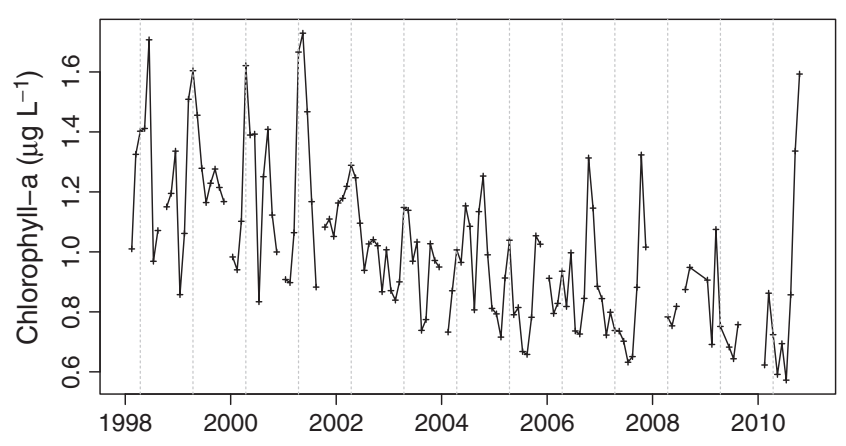

Fig. 2 Monthly lakewide mean surface chlorophyll concentration from SeaWiFS remote sensing imagery for the period 1998 through 2010 (Yousef et al., 2014). Vertical dashed lines indicate April of each year.

investigators (Fahnenstiel et al., 2010b; Kerfoot et al., 2010; Vanderploeg et al., 2010; Yousef et al., 2014). The winter-spring bloom is comprised of energy-rich diatoms, and the loss of this food source to pelagic and benthic invertebrates has consequences throughout the food web, including for fish (Madenjian et al., 2006; Nalepa et al., 2009; Pothoven, Fahnenstiel \& Vanderploeg, 2010). Several lines of evidence implicate filter feeding by D. r. bugensis in the disappearance of the winter-spring bloom: (i) loss of the winter-spring bloom was coincident with establishment of a large population of D. r. bugensis, (ii) the reduction in chlorophyll-a concentration and primary production occurred mainly in the isothermal period when benthic filter feeding can draw down phytoplankton abundance throughout the entire water column (Fahnenstiel et al., 2010b; Kerfoot et al., 2010), and (iii) measured clearance rates of D. r. bugensis could exceed the spring phytoplankton growth rate, assuming a well-mixed water column (Vanderploeg et al., 2010). Alternate explanations for the loss of the winter-spring bloom, including reduced phosphorus loads, and increased zooplankton grazing and climate change, were found to be unsatisfactory (Fahnenstiel et al., 2010b). Our study provides a new approach for assessing the relationship between dreissenid filter feeding and the loss of the winter-spring bloom by considering the spatial association between the reduction in chlorophyll (from the pre$D$. r. bugensis period to the post-D. r. bugensis period) and the filter-feeding intensity of D. r. bugensis.

\section{Methods}

Physical characteristics of Lake Michigan

Lake Michigan is one of the five Laurentian Great Lakes of North America (Fig. 3). It is an oligotrophic lake 


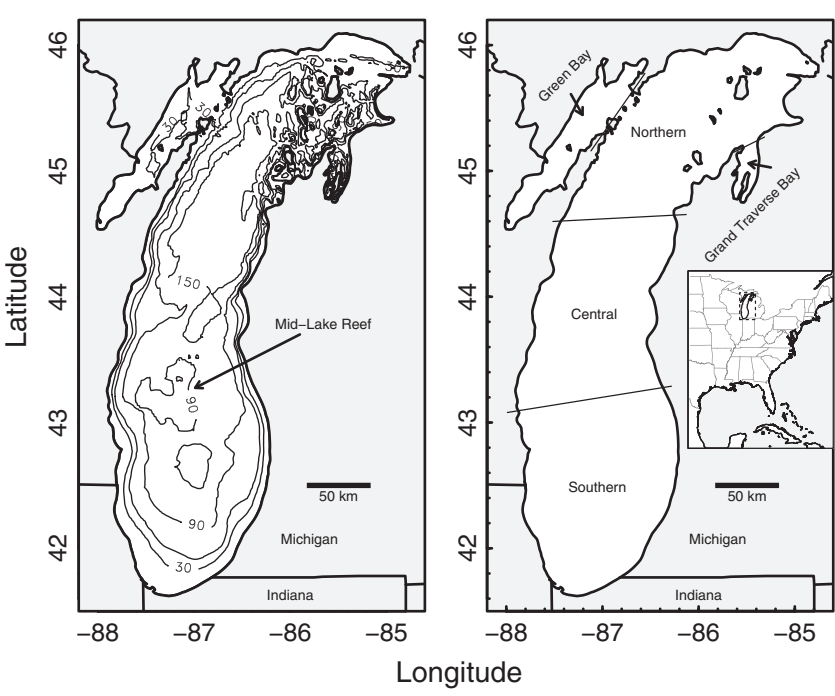

Fig. 3 Map of Lake Michigan showing bathymetry contours and regions that were used to summarise results. The inset in the right panel shows the location of Lake Michigan in North America.

with a surface area of $57800 \mathrm{~km}^{2}$, a catchment of $118000 \mathrm{~km}^{2}$, a volume of $4947 \mathrm{~km}^{3}$ and a maximum depth of $281 \mathrm{~m}$ (Coordinating Committee on Great Lakes Basic Hydraulic and Hydrologic Data, 1977). It is dimictic, with periods of complete vertical mixing in spring and autumn with summer stratification and variable stratification and ice cover during winter (Wang et al., 2012). Dates of stratification vary from year to year and, in general, the surface mixed layer (SML) varies seasonally and temporally from a few metres deep at the onset of summer stratification (May-June) to 10$20 \mathrm{~m}$ in July-August (Beletsky, Schwab \& McCormick, 2006). In the autumn, the SML increases due to higher winds and convection (surface cooling), leading into the isothermal period (December-April) when the water column is vertically well mixed except for intermittent winter stratification when the surface is colder than $4{ }^{\circ} \mathrm{C}$ (Beletsky \& Schwab, 2001). Surface water temperature in the summer reaches c. $20{ }^{\circ} \mathrm{C}$. At depths $>$ c. $30 \mathrm{~m}$, nearbottom water temperature is $c .4{ }^{\circ} \mathrm{C}$ for most of the year, except in late summer and autumn when the deepening of the SML may bring warmer water (typically $<10{ }^{\circ} \mathrm{C}$ ) to the bottom.

\section{Observed dreissenid mussel biomass}

Numerical densities of D. polymorpha and D. r. bugensis were obtained from samples collected with a Ponar grab (sampling area $=0.046 \mathrm{~m}^{2}$ ) in July-August of 1994/1995, 2000, 2005 and 2010 (Nalepa et al., 2008, 2014). The number of stations sampled was 90, 157, 160 and 144 in each of the four periods, respectively. Station locations were largely the same in 2000, 2005 and 2010, but differed in 1994/1995. Numerical density was converted to Dreissena biomass using length-mass relationships and length frequency distributions (Nalepa et al., 2009, 2014). Samples were collected in triplicate at each station and were averaged by station and year for the development of the geostatistical model. We report Dreissena biomass in units of grams ash-free dry tissue mass (g AFDM). Biomass may be converted to other units through approximate empirical relationships obtained from $D$. polymorpha specimens: $1 \mathrm{~g}$ dry tissue mass $=0.88 \mathrm{~g}$ AFDM, $1 \mathrm{~g}$ dry tissue mass $=0.46 \mathrm{~g}$ carbon (Nalepa et al., 1993). We chose to conduct our analysis on total Dreissena biomass (sum of D. polymorpha and D. r. bugensis) because clearance rates of the two species, normalised to biomass, are not significantly different (Vanderploeg et al., 2010), and D. r. bugensis dominated total biomass in years for which there were noticeable impacts.

\section{Geostatistical model}

We applied a geostatistical modelling framework (Diggle \& Ribeiro, 2007; Chiles \& Delfiner, 2009) that has been previously used with fisheries benthic trawl surveys (Jardim \& Ribeiro, 2007, 2008) and bottom-water hypoxia surveys (Obenour et al., 2013; Zhou et al., 2013). To avoid potential confusion, we emphasise that the geostatistical model predicts dreissenid biomass across space, but it does not make predictions across time. The geostatistical model was implemented using the R package (R Core Team, 2012) 'geoR' (Ribeiro \& Diggle, 2001).

The following is a brief explanation of the geostatistical modelling framework, which is described in detail elsewhere (Ribeiro \& Diggle, 2001; Diggle \& Ribeiro, 2007). Data consist of individual response observations $z_{\mathrm{i}}$ associated with locations $x_{\mathrm{i}}$, which are a subset of the observation region. In the geostatistical model, the response $Z(x)$ is related to an unobserved stochastic process $S(x)$ called a 'signal', which fluctuates around an underlying deterministic trend $\mathbf{F}(x) \beta$. The signal, $S(x)$, is a stationary Gaussian process characterised by a spatial variogram (covariance function) that is typically fitted through variogram analysis or likelihood estimation (Ribeiro \& Diggle, 2001). Here, a spherical covariance function (Ribeiro \& Diggle, 2001), fitted using restricted maximum likelihood (Zimmerman, 2010), was found to produce robust model parameter estimates. Covariance parameters include $\tau^{2}, \sigma^{2}$ and $\varphi$, which are commonly referred to as the nugget, partial sill and range, respectively. Coincident observations have a covariance of 
$\sigma^{2}+\tau^{2}$; observations at very small (but nonzero) separation distances have a covariance of $\sigma^{2}$; and, as the separation distance increases to the range $(\varphi)$, the covariance between observations decreases from $\sigma^{2}$ to zero (and conversely, the variance between observations increases from $\tau^{2}$ to $\sigma^{2}+\tau^{2}$ ). For this study, a Box-Cox transformation $(\lambda=0.3)$ of the response was found to substantially improve the Gaussian properties of the signal (Box \& Cox, 1964; Ribeiro, Christensen \& Diggle, 2003). Because the Box-Cox transformation cannot be applied to zero values, an offset of $+0.01 \mathrm{~g} \mathrm{AFDM} \mathrm{m}^{-2}$ was first applied to all observations, and it was subsequently removed from all model predictions after back-transforming to the original scale.

The deterministic trend component (or 'drift'), $\mathrm{F}(x) \beta$, characterises the underlying, large-scale spatial and bathymetric trends in $Z(x)$. Here, $\mathbf{F}(x)$ is a design matrix with covariate elements of the type $f_{\mathrm{j}}\left(x_{\mathrm{i}}\right)$, a measurement of the $j$ th covariate at the $i$ th location. Regression parameters, $\beta_{\mathrm{j}}$, are estimated through generalised least squares, taking into account the covariance structure of the response. When implemented with covariates, in this way, the geostatistical model is often referred to as a 'Universal Kriging' model (Chiles \& Delfiner, 2009).

In our model, the design matrix $\mathbf{F}(x)$ included both bathymetric and spatial-coordinate covariates. The depth dependence of Dreissena biomass was found to be nonlinear and non-monotonic, with a maximum abundance occurring at an intermediate-depth range. To accommodate this pattern within the geostatistical model, we considered two approaches: (i) polynomial depth dependence and (ii) categorical depth variable (the depth range was divided into a series of categorical variables representing different depth intervals). Polynomial functions did not conform well to the observed depth dependence; a second-order polynomial did not capture the asymmetry in the trend around the depth of maximum mussel density, and higher-order polynomials were more likely to produce unrealistic values at depth extremes. In contrast, the categorical depth variable conformed well to observed trends at shallow and deep extremes without being constrained to follow a prescribed functional relationship. Therefore, we selected the categorical depth variable as a predictor in the geostatistical model. A range of depth interval widths (10, 20 and $25 \mathrm{~m}$ ) was considered for the categorical depth variable, and an algorithm was developed to combine depth intervals systematically, when necessary, to ensure a sufficient number of observations $(n>9)$ within each of the final intervals. Depth intervals with mean biomass $<0.1 \mathrm{~g}^{\mathrm{AFDM} \mathrm{m}}{ }^{-2}$ were not modelled geostatistically because their associated biomass was small and because inclusion of a large number of zero-value observations did not conform well to the Gaussian signal assumption. Thus, the depth covariates, $D_{\mathrm{k}}$, include categorical variables for each of the $k$ depth intervals included in the geostatistical formulation. Spatial-coordinate covariates were based on $X$ and $Y$, the UTM easting and northing, respectively; both linear and quadratic spatial trends were considered (using $X, Y, X^{2}$ and $Y^{2}$ ). Each of the three sets of depth covariates (based on 10, 20 and $25 \mathrm{~m}$ candidate depth interval widths), along with all possible combinations of linear and quadratic spatial trends, was evaluated based on a leave-one-out cross-validation and the Bayesian information criterion (BIC) (Schwarz, 1978; Ribeiro \& Diggle, 2001). The preferred depth interval width was selected based on comparison of cross-validation skill statistics, including the coefficient of determination (COD) and the per cent bias in predicted versus observed results (on the original, untransformed scale). Linear and quadratic trends (with spatial coordinates) were then selected based on the BIC score.

Spatial prediction was performed over a $2-\mathrm{km}$ grid covering all of Lake Michigan. Grid and observation coordinates were projected to UTM Zone 16 North to minimise distortion in distance and area calculations. For deterministic trend development, spatial coordinates were converted to units of $10^{5} \mathrm{~m}$ to avoid scale mismatch issues among covariates. Bathymetry was obtained from the NOAA National Geophysical Data Center (www.ngdc.noaa.gov/mgg/greatlakes/greatlakes.html).

After the model was parameterised, conditional simulations (Ribeiro \& Diggle, 2001; Chiles \& Delfiner, 2009) were conducted by sampling from the uncertainty in $S$ $(x)$ and $\beta$ at prediction grid locations $x$, thus creating a large number of realisations (1000) of the spatial distribution of $Z(x)$ consistent with the original point observations. Prediction grid locations corresponding to depth intervals excluded from the geostatistical model (as described above) were simulated by randomly sampling from the excluded observations. From this ensemble of realisations, probabilistic estimates of spatially aggregated quantities were then derived (e.g. Obenour et al., 2013). Specifically, the mean, median and $90 \%$ confidence intervals (based on the 5\% and $95 \%$ quantiles) for biomass were calculated across the entire lake and within specific regions.

\section{Dreissena filter-feeding intensity, $F_{C}$}

We calculated the filter-feeding intensity $\left(F_{\mathrm{C}}\right.$, day $\left.^{-1}\right)$ by Dreissena as $F_{C}=B \times C / d$, where $B$ is the biomass, $C$ is 
the biomass-specific volume of water cleared by filter feeding per unit time, and $d$ is the local bathymetric depth (Vanderploeg et al., 2010). We used $C=12 \mathrm{~mL}$ (mg AFDM $)^{-1} \mathrm{~h}^{-1}$ at $3{ }^{\circ} \mathrm{C}$, based on experiments with $D . r$. bugensis from Lake Michigan feeding on Cryptomonas, a preferred food of Dreissena and a representative alga of the Lake Michigan winter-spring phytoplankton assemblage (Vanderploeg et al., 2010).

The quantity $F_{C}$ may be thought of as the first-order rate coefficient for phytoplankton mortality due to dreissenid grazing under conditions of a vertically wellmixed water column. Vanderploeg et al. (2001, 2002, 2010) used $F_{C}$ to predict the effect of mussels on summer and winter assemblages of phytoplankton, based on the observation that dreissenids filter a broad range of particle sizes. Higgins \& Vander Zanden (2010) used $F_{C}$ as a predictor of impact in meta-analyses of Dreissena across systems. Vanderploeg et al. (2010) related $F_{C}$ to an average net phytoplankton growth rate of 0.06 day $^{-1}$ during spring isothermal conditions in Lakes Michigan, Erie, Huron and Ontario (Fahnenstiel et al., 2000) as a benchmark to estimate the ability of Dreissena populations to affect the winter-spring phytoplankton bloom.

\section{Satellite-derived chlorophyll concentration}

SeaWiFS (Sea-viewing Wide Field-of-view Sensor) data were downloaded from NASA's Ocean Colour data archive (http://oceancolor.gsfc.nasa.gov). Level 2 (L2) images were used for our analysis with c. 1-kilometre $(\mathrm{km})$ pixel resolution for final products. SeaDAS7 software was used to process and map the acquired data to UTM (Zone 16 North) projection. SeaWiFS L2 chlorophyll maps were produced using the NASA OC4 algorithm, with methods fully described in the study of Yousef et al. (2014). Band ratio algorithms for chlorophyll, such as OC4, are suitable for waters in which chlorophyll is the main colour-producing agent, and are known to suffer from artefacts due to interference from other constituents of surface waters, including suspended mineral particles and coloured dissolved organic matter. Kerfoot et al. (2008) found good agreement between SeaWiFS-derived chlorophyll and in situ measurements in Lake Michigan $\left(R^{2}=0.874\right)$. Comparison of SeaWiFS OC3 chlorophyll retrieval (a band ratio algorithm similar to OC4) to in situ chlorophyll measurements indicated that OC3 produced acceptable retrievals for open waters of Lake Michigan (Shuchman et al., 2013; their Table 3). Comparison of SeaWiFS OC4 chlorophyll to several hundred in situ chlorophyll measurements in the Great Lakes indicated good agreement up to chlorophyll concentration of $3 \mu \mathrm{g} \mathrm{L}^{-1}$ with increasing bias at higher chlorophyll concentration (Lesht, Barbiero \& Warren, 2013; their Fig. 4). To avoid potential artefacts introduced by optically complex waters, we excluded areas from our analysis with chlorophyll concentrations $>3 \mu \mathrm{g} \mathrm{L}^{-1}$ in any given SeaWiFS image. Chlorophyll concentrations $>3 \mu \mathrm{g} \mathrm{L}^{-1}$ were limited to nearshore areas and to eutrophic Green Bay. In addition, we excluded areas shallower than $15 \mathrm{~m}$ to avoid artefacts caused by bottom reflectance. Monthly mean chlorophyll concentration was determined by averaging the cloud-free pixels of each daily satellite image over the month. We excluded monthly mean images with $<50 \%$ spatial coverage from the analysis, which mainly occurred in November to January due to greater cloud cover in these months.

\section{Regression of chlorophyll reduction on filter-feeding intensity}

A regression analysis was conducted to test the hypothesis that the reduction in chlorophyll concentration (before and after the invasion of D. r. bugensis), $\Delta C h l$, was spatially associated with the filter-feeding intensity, $F_{C}$, during the isothermal period (when the water column is vertically well mixed). To account for seasonal trends in chlorophyll concentration when estimating $\Delta \mathrm{Chl}$, we compared chlorophyll concentration within the same month for different years. In our regression analysis, we accounted for three sources of uncertainty in the regression parameter estimates: (i) spatial and interannual variation in pre- and post-invasion chlorophyll, (ii) parameter estimation by least-squares regression and (iii) estimation of dreissenid biomass spatial distribution by the geostatistical model. These sources of uncertainty were addressed by means of a sampling-based Monte Carlo method in which we sampled from the ensembles of pre-invasion years (1998-2001), post-invasion years (2005-2010) and realisations of mussel spatial distribution from the geostatistical model. Samples of dreissenid biomass distribution for post-mussel years were determined through linear interpolation between the geostatistical conditional simulations of biomass distribution for 2005 and 2010. Each Monte Carlo sample produced a map of $\Delta C h l$ and a map of post-invasion $F_{\mathrm{C}}$ on the $2-\mathrm{km}$ prediction grid, and 1000 such samples were created in total. To avoid influence of spatial autocorrelation on the regression, $\triangle C h l$ was averaged lakewide within intervals of $F_{C}$. The ten intervals of $F_{C}$ were selected to give an equal number of pixels within each interval (c. 1000). Thus, each sample produced 10 data points on which 

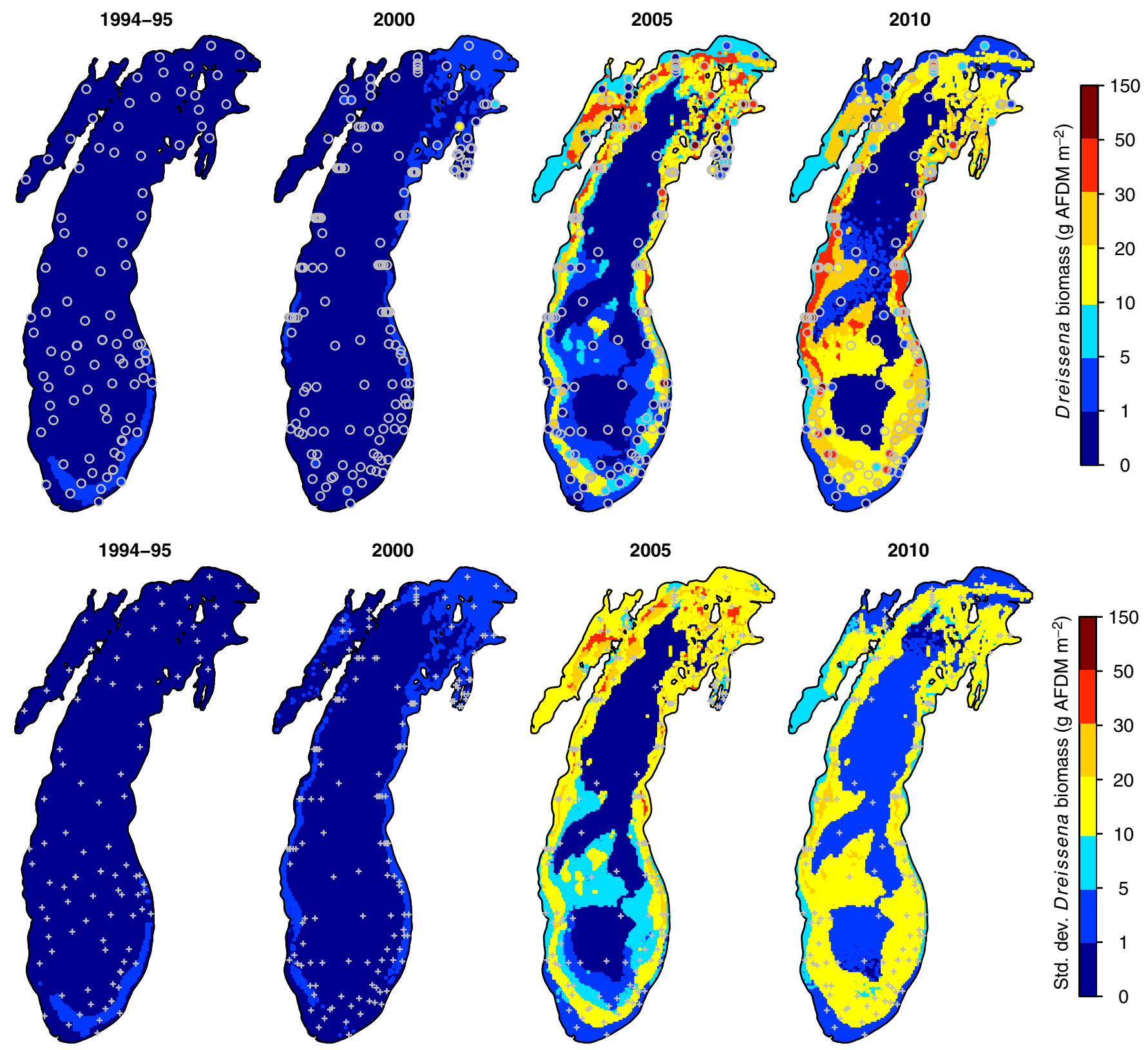

Fig. 4 Spatial distribution of mean (top row) and standard deviation (bottom row) of dreissenid mussel biomass from geostatistical conditional simulations. Observed values are shown as circles, in the same colour bar scale.

the regression was conducted. A two-segment, piecewise linear regression was selected. Regression parameter estimation was conducted using the $\mathrm{R}$ package 'segmented' (Muggeo, 2003, 2008). The Monte Carlo sampling method resulted in an ensemble of 1000 regression parameter estimates. To account for uncertainty in estimation of the parameters by regression, the ensemble was enlarged to 10000 by sampling $(n=10)$ from the uncertainty (i.e. standard error) of each of the 1000 parameter estimates. The final parameter estimate and confidence interval were taken from the percentiles of the ensemble of parameter estimates.

\section{Results}

The maps of dreissenid mussel biomass (Fig. 4) produced by the geostatistical model show the spatial patterns of the invasion of Lake Michigan by D. polymorpha and D. r. bugensis. The geostatistical model expands upon the benthic survey data of Nalepa et al. (2014) by predicting biomass in locations that were not sampled to provide a distinct visualisation of the ring of high dreissenid mussel biomass that developed around the lake within an intermediate-depth band in 2005, with further expansion of the depth range in 2010. The categorical 

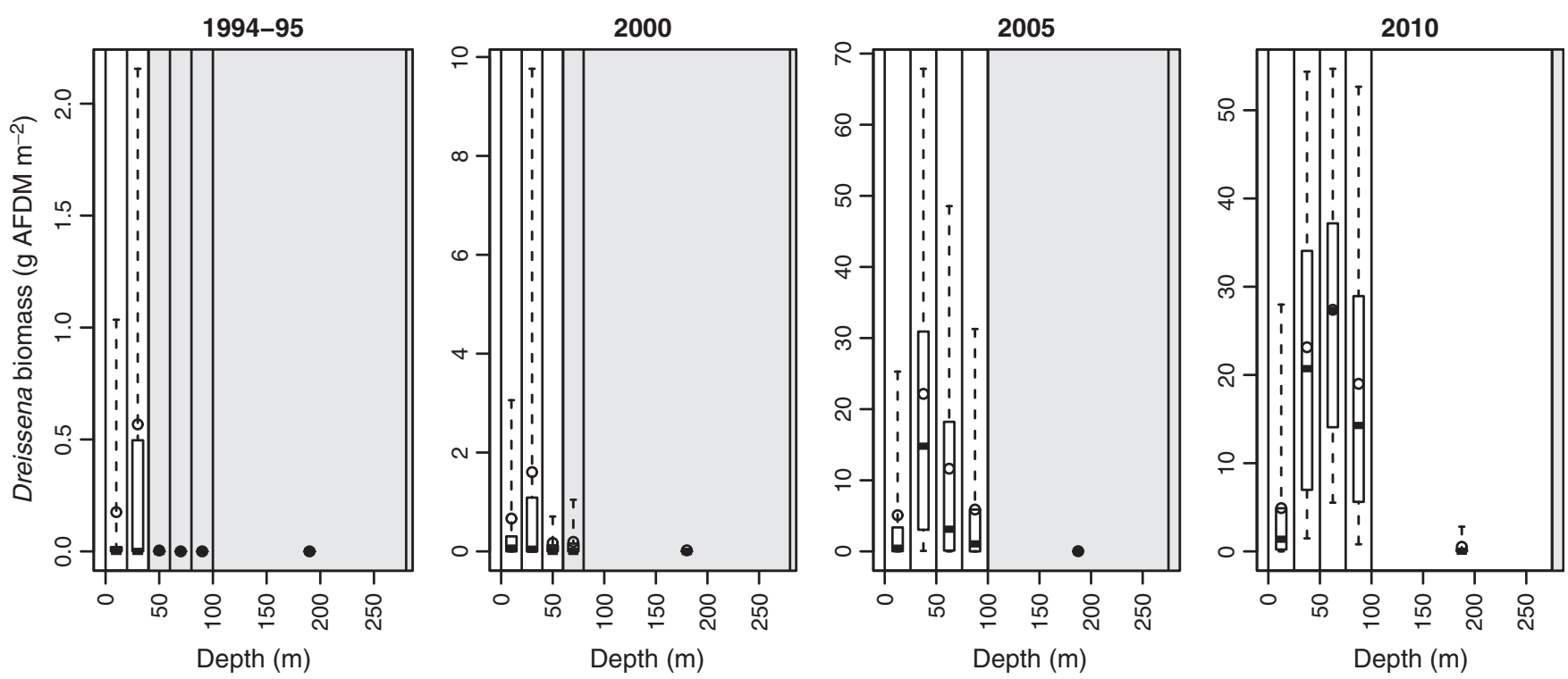

Fig. 5 Boxplots of observed dreissenid mussel biomass as related to station depth where samples were collected. The bathymetric depth intervals that were used to create the categorical depth variable in the covariate trend model are indicated for each year in the study period (vertical lines). The depth ranges shaded in grey had minimal biomass and were treated separately from the geostatistical model. Boxplots are defined as in Fig. 1. Note that the $y$-axis scale differs among years.

depth intervals (Fig. 5) and spatial coordinates were found to be significant explanatory variables in models for each period (Table 1).

The ability to quantify the spatial prediction uncertainty is an important outcome of the geostatistical modelling approach applied here. The standard deviation of the conditional simulations is an indicator of the spatial prediction uncertainty (Fig. 4, bottom). Throughout the lake, standard deviations are comparable in magnitude to the best estimates of mussel biomass (Fig. 4), reflecting the fact that variance increases with increasing biomass (motivating the Box-Cox transformation of the observations). The sum of $\tau^{2}+\sigma^{2}$, representing the total variance of the observations around the covariate trend, was lowest in 1994-1995 and increased substantially in later periods, consistent with the substantial increase in

Table 1 Geostatistical covariate trend model, skill statistics and covariance parameters for each year. Per cent bias and coefficient of determination (COD) were determined by leave-one-out crossvalidation. The covariates are the categorical depth variables $D_{\mathrm{k}}$, and spatial coordinates $X$ and $Y$ (UTM easting and northing, respectively). The covariance parameters $\tau^{2}$ and $\sigma^{2}$ are the nugget and partial sill (for Box-Cox transformed Dreissena biomass), and $\varphi$ is the range of spatial correlation $(\mathrm{km})$

\begin{tabular}{llrrrrr}
\hline Year & Covariates & Pct. bias & COD & $\tau^{2}$ & $\sigma^{2}$ & $\varphi$ \\
\hline $1994-1995$ & $D_{\mathrm{k}}+X+Y$ & -9.3 & 0.27 & 0.0 & 0.7 & 14.0 \\
2000 & $D_{\mathrm{k}}+X$ & -17.9 & 0.13 & 1.4 & 0.5 & 96.1 \\
2005 & $D_{\mathrm{k}}+X+Y+X^{2}+Y^{2}$ & -0.4 & 0.27 & 4.5 & 2.8 & 29.3 \\
2010 & $D_{\mathrm{k}}+X+Y+Y^{2}$ & 2.4 & 0.46 & 0.4 & 2.5 & 2.5 \\
\hline
\end{tabular}

(C) 2015 John Wiley \& Sons Ltd, Freshwater Biology, 60, 2270-2285 the variance of observations apparent in Fig. 5. This variability does not have a high degree of spatial correlation, as the range of spatial correlation $(\varphi)$ was only 14.0 and $2.5 \mathrm{~km}$ in 1994-1995 and 2010, respectively. The range of spatial correlation was larger in 2000 and 2005, but in these years the greatest portion of the variance was uncorrelated (i.e. $\sigma^{2}<\tau^{2}$ ). Due to the limited spatial correlation in the fitted model, proximity to sampling locations does not appear to substantially affect predictive uncertainty (Fig. 4, bottom), and although sampling effort increased from 1994 to 1995 to later periods, there was no net reduction in predictive uncertainty.

To summarise how biomass varied spatially and through time, biomass estimates developed through conditional simulations were aggregated lakewide and for the northern, central and southern regions of the lake (Fig. 3), and for the same depth intervals used by Nalepa et al. (2009). Lakewide total biomass increased significantly for each five-year period from 1994/1995 to 2010 (Table 2), despite the fact that biomass declined or remained constant in some regions in the period 20052010 (Fig. 6). The highest biomass ( $30-40 \mathrm{~g} \mathrm{AFDM} \mathrm{m}^{-2}$ ) occurred in the northern region in 2005 in the 30- to $50-\mathrm{m}$ depth range and subsequently declined in 2010 (Fig. 6). However, biomass increased continuously over the study period in the southern region for all depth ranges, and at depths $>50 \mathrm{~m}$ over all regions.

The spatial distribution of dreissenid filter-feeding intensity, $F_{C}$ (Fig. 7, top), was similar to that of mussel 
biomass (Fig. 4), but was intensified in shallower areas, as expected from the appearance of $d$ in the denominator of the $F_{C}$ relationship. In 2005 and 2010, April chlorophyll (Fig. 7, bottom; Yousef et al., 2014) was greatly reduced lakewide, relative to 2000 and earlier (Figs 2 \& 7), indicating near disappearance of the winter-spring phytoplankton bloom. A white contour line was added

Table 2 Mean and percentiles of the Lake Michigan total Dreissena biomass from the conditional simulations, millions of $\mathrm{kg}$ ash-free dry mass

\begin{tabular}{lrrrrrr}
\hline Year & Mean & \multicolumn{1}{c}{5} & \multicolumn{1}{c}{25} & \multicolumn{1}{c}{50} & \multicolumn{1}{c}{75} & 95 \\
\hline $1994-1995$ & 6 & 4 & 5 & 6 & 7 & 8 \\
2000 & 18 & 14 & 17 & 18 & 20 & 23 \\
2005 & 408 & 338 & 376 & 406 & 437 & 485 \\
2010 & 610 & 547 & 582 & 607 & 636 & 680 \\
\hline
\end{tabular}

to the chlorophyll plots in Fig. 7 to indicate the region in which $F_{\mathrm{C}}$ exceeded the benchmark net growth rate of phytoplankton during the winter-spring bloom in Lake Michigan of $0.06 \mathrm{day}^{-1}$, and we would expect the winter-spring bloom to be greatly reduced in this region. In 2005, and to a greater extent in 2010, low chlorophyll concentrations are evident within the white contour lines (Fig. 7), providing observational evidence for a direct impact of dreissenid mussel filter feeding on the winterspring bloom in Lake Michigan.

The geostatistical model results allow us to estimate when the filter-feeding intensity, $F_{C}$, first exceeded benchmark phytoplankton growth rate within specific regions and depth ranges. In 2000, $F_{C}$ was much $<0.06$ day $^{-1}$ over most of Lake Michigan, but slightly exceeded that value in the northern region (Fig. 8). In 2005, $F_{C}$ exceeded
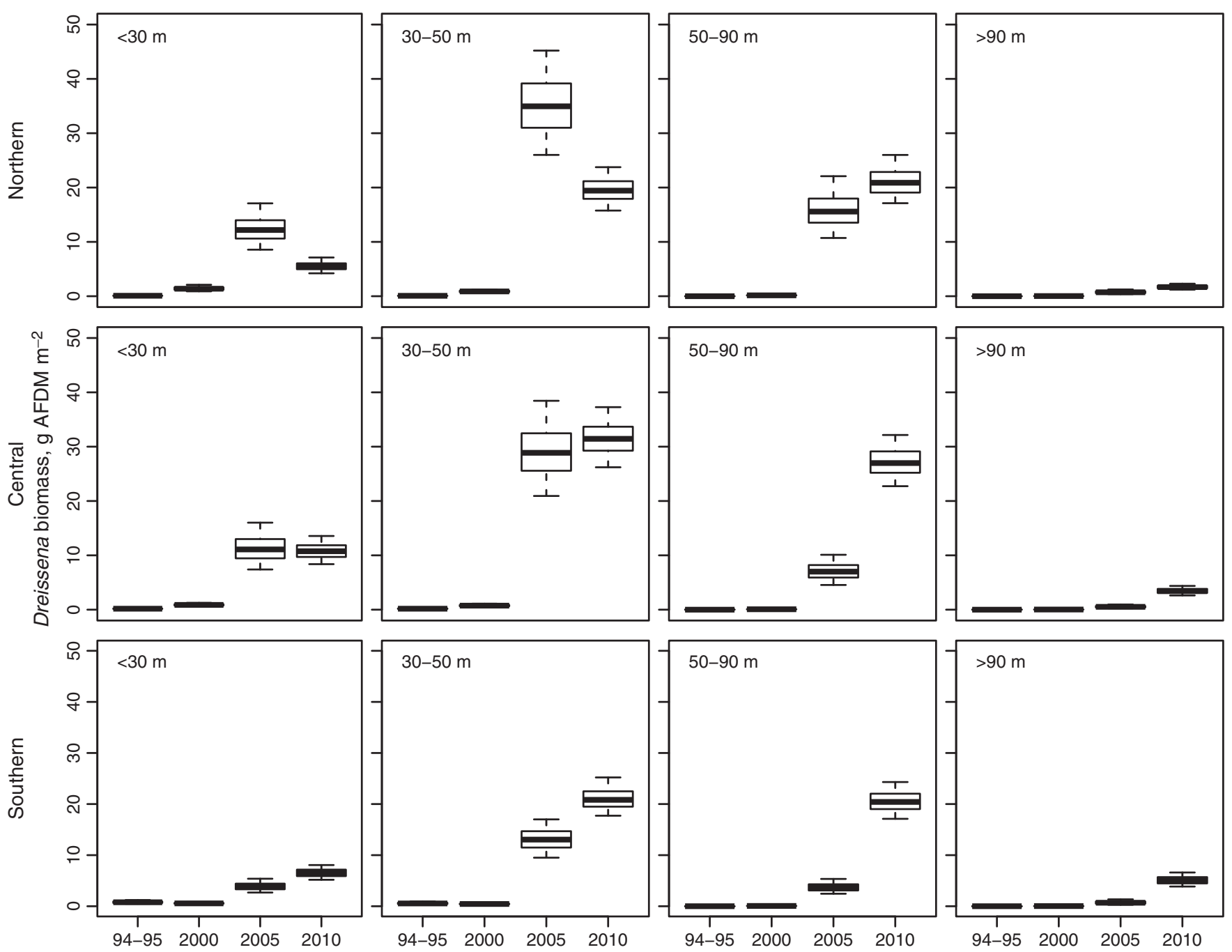

Fig. 6 Mean dreissenid mussel biomass within regions of Lake Michigan indicated in Fig. 3. Boxplots indicate the 5th, 25th, 50th, 75th and 95th percentiles of the 1000 values obtained from the conditional simulations. 

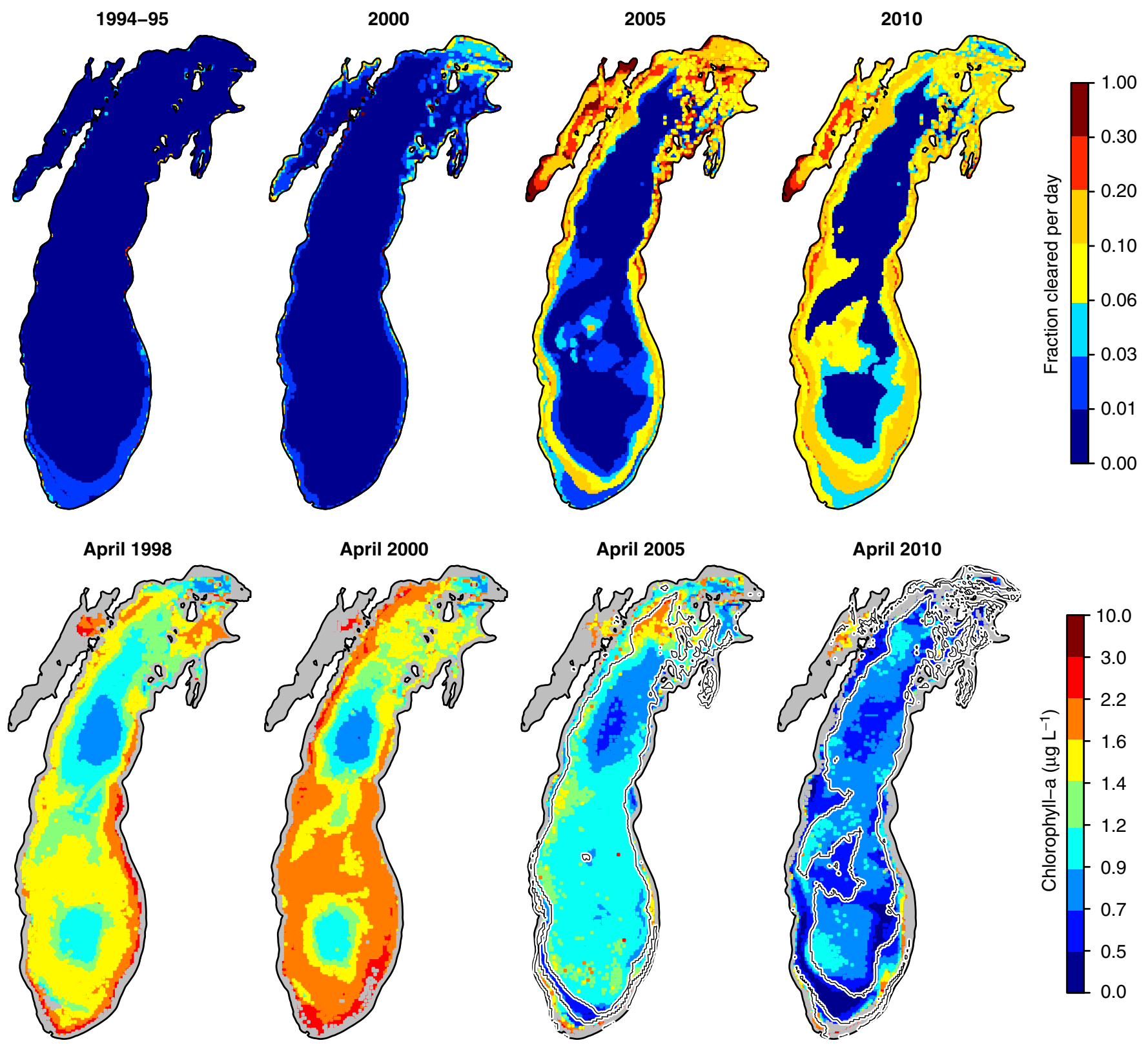

Fig. 7 Spatial distribution of the fraction of the water column cleared per day by Dreissena filter feeding, $F_{\mathrm{C}}$ (top row), and the mean April chlorophyll concentration for corresponding years from the SeaWiFS satellite (Yousef et al., 2014) (bottom row). The earliest year available for

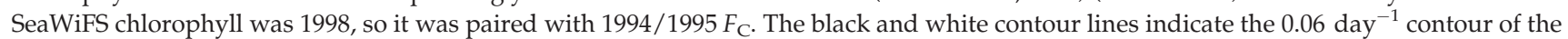
fraction cleared per day, which is the benchmark phytoplankton growth rate during the winter-spring bloom (Vanderploeg et al., 2010). Areas shaded in grey were excluded from the analysis by quality screening criteria applied to the satellite-derived chlorophyll data (see Methods).

0.06 day $^{-1}$ in all regions for $<30$ and $30-$ to $50-\mathrm{m}$ depth ranges. In 2010, compared to 2005, $F_{C}$ declined in the northern region, remained constant in the central region and continued to increase in the southern region. In the 50- to $90-\mathrm{m}$ depth range, $F_{\mathrm{C}}$ first exceeded 0.06 day $^{-1}$ on a lakewide basis in 2010, resulting in a large expansion of the area impacted by dreissenid grazing (Fig. 7).

To test our hypothesis that the post-invasion reduction in chlorophyll, $\triangle \mathrm{Chl}$, was spatially associated with
Dreissena filter-feeding intensity, $F_{\mathrm{C}}$, we conducted a regression analysis. The two-segment, piecewise linear regression model used (Fig. 9) has four parameters, each of which may be interpreted to provide information relevant to our hypothesis: (i) $\gamma_{0}$, the $y$-axis intercept, $\Delta C h l$ at $F_{\mathrm{C}}=0$, represents the reduction in chlorophyll at locations that were not locally affected by Dreissena filter feeding, (ii) $\gamma_{1}$, the slope of the line segment from $F_{\mathrm{C}}=0$ to $F_{\mathrm{C}}=\gamma_{\mathrm{b}}$, is expected to be 

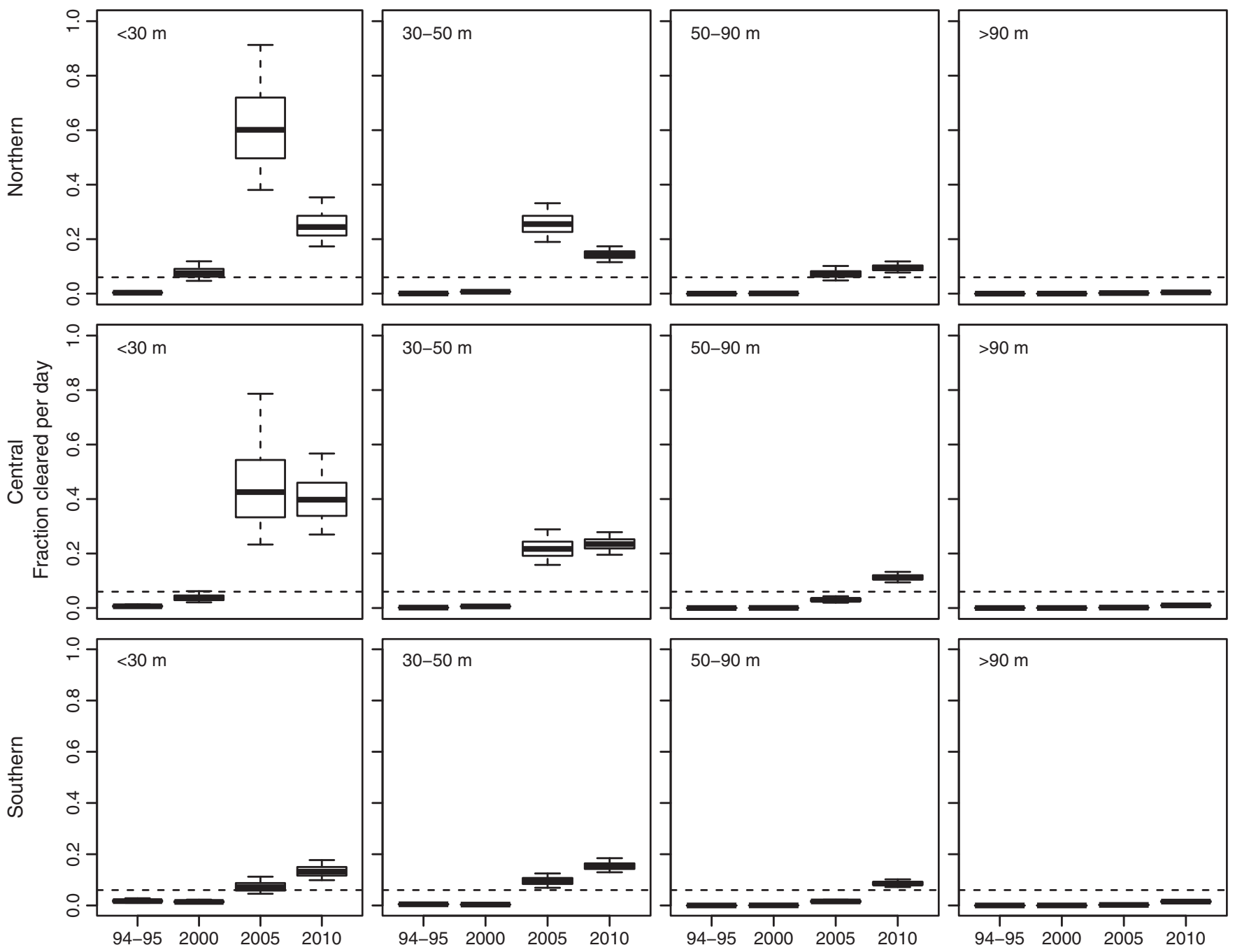

Fig. 8 Fraction of the water column cleared per day by Dreissena filter feeding, $F_{C}$, summarised over the regions indicated in Fig. 3 . The dashed line indicates the 0.06 day $^{-1}$ level of fraction cleared per day. Boxplots are defined as in Fig. 6.

negative if $\Delta C h l$ is spatially associated with $F_{\mathrm{C}}$, (iii) $\gamma_{\mathrm{b}}$, the breakpoint value of $F_{C}$ for the piecewise regression, is expected to be near the benchmark phytoplankton growth rate of 0.06 day $^{-1}$ and (iv) $\gamma_{2}$, the slope of the line segment for $F_{C}>\gamma_{b}$, is expected to have a slope of zero because the local impact of Dreissena filter feeding is expected to saturate at $F_{\mathrm{C}}$ greater than the phytoplankton growth rate.

Results of the regression analysis indicated significant negative values of $\gamma_{0}$ for February, April to August, and December (Fig. 10, top), indicating a significant post-invasion reduction in chlorophyll concentration even at locations where local filter-feeding intensity was near zero. Significant negative $\gamma_{1}$ values were found for December to April (Fig. 10, bottom), indicating that filter feeding had a significant localised effect up to some threshold value in $F_{C}\left(\gamma_{b}\right)$. As expected, these significant local effects occurred in months when the lake was relatively well mixed vertically. Also consistent with our hypothesis was the finding that $\gamma_{1}$ values were not significantly different from zero for months associated with summer stratification (May to November), with the exception of June, which had a significant positive value of $\gamma_{1}$. For months associated with the winter-spring bloom (February-April), $\gamma_{\mathrm{b}}$ was 0.03 day $^{-1}(0.00-0.08$, 95\% CI for the three months combined), not significantly different from the benchmark phytoplankton growth rate of 0.06 day $^{-1}$. Finally, $\gamma_{2}$ was not significantly different from zero (95\% CI does not include zero) for any month, indicating that the reduction in chlorophyll due to the local effect of Dreissena filter feeding was saturated for $F_{\mathrm{C}}>\gamma_{\mathrm{b}}$.

(C) 2015 John Wiley \& Sons Ltd, Freshwater Biology, 60, 2270-2285 


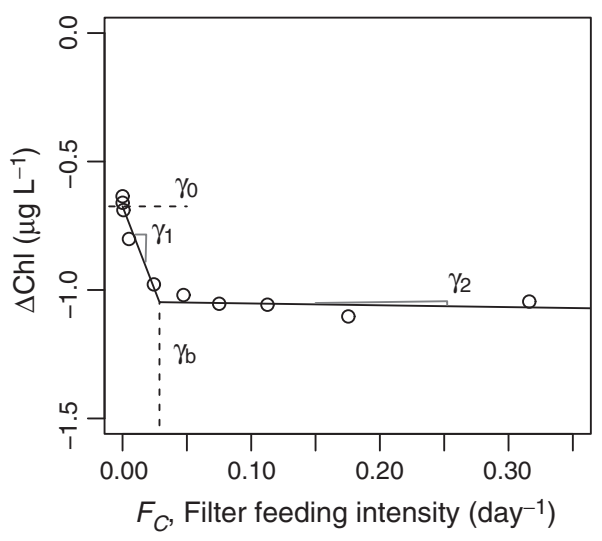

Fig. 9 An example of fitting a piecewise linear regression model of spatially associated values of filter-feeding intensity and the change in chlorophyll concentration $(\Delta C h l$, pre- $D$. r. bugensis period to post-D. r. bugensis period). In this example, the month is April, the pre-D. r. bugensis year is 1999, and the post-D. r. bugensis year is 2009. Each point in the plot represents the mean $\Delta C h l$ for an interval of $F_{\mathrm{C}}$ (c. 1000 2-km pixels per interval; point shown at mean value of $F_{\mathrm{C}}$ for each interval).

\section{Discussion}

Before the invasion of Lake Michigan by D. r. bugensis, a late winter to spring (March-May) phytoplankton bloom was typical (Fahnenstiel \& Scavia, 1987; Fahnenstiel et al., 2000; Kerfoot et al., 2008, 2010). Lake Michigan was often vertically well mixed during the spring bloom (Fahnenstiel et al., 2000), resulting in spatial patterns of winter-spring chlorophyll concentrations related to bathymetry: higher chlorophyll in moderate depth regions where SML-mean light exposure is higher, and low chlorophyll in the deep central basins where SMLmean light exposure is least (Fig. 7; 1998, 2000).

Initiation of the winter-spring phytoplankton bloom in lakes and oceans is sensitive to the thickness of the surface mixed layer which, in combination with the light attenuation coefficient, controls the mean light exposure of phytoplankton cells (Sverdrup, 1953; Fahnenstiel et al., 2000; Siegel, Doney \& Yoder, 2002). In order for the winter-spring phytoplankton bloom to begin, the population growth rate must exceed loss processes, which include phytoplankton respiration, excretion, sinking and losses to heterotrophic grazing; thus, the critical light level to initiate the winter-spring bloom (i.e. compensation irradiance) increases with increasing losses of phytoplankton to heterotrophic grazing (Sverdrup, 1953; Siegel et al., 2002). If grazing pressure on phytoplankton is sufficiently high, then the compensation irradiance may not be exceeded until the thickness of the surface mixed layer has been reduced by summer
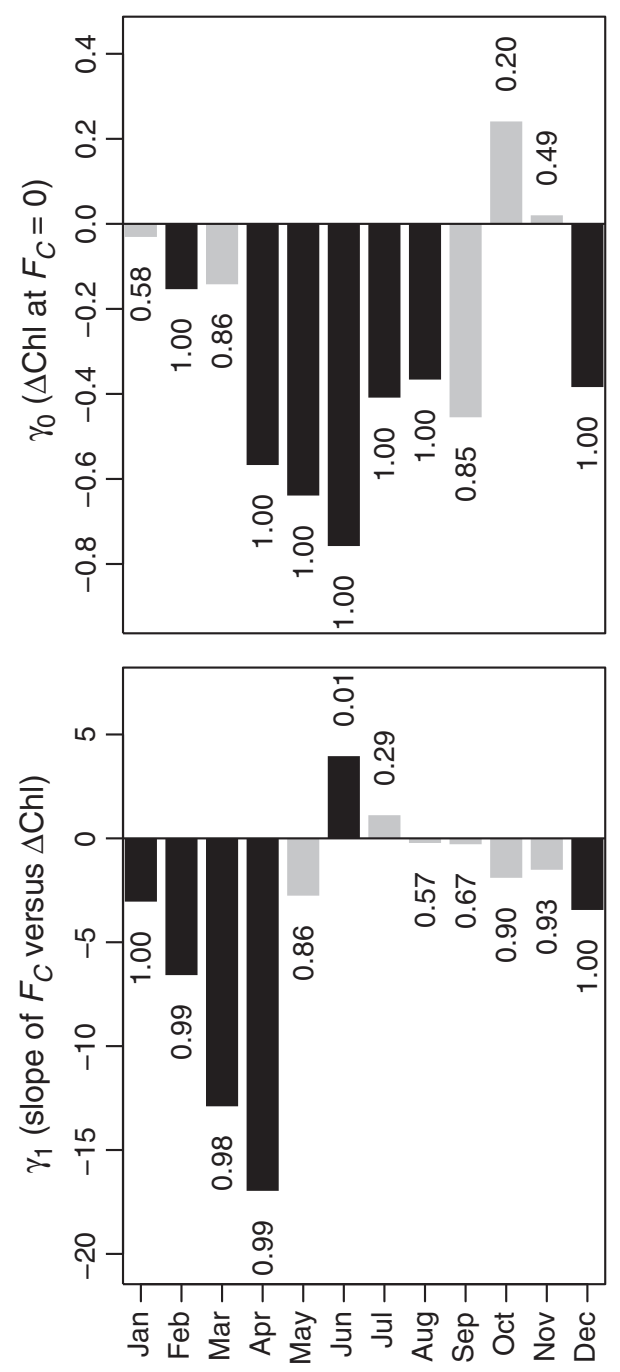

Fig. 10 Parameter estimates by month for the piecewise linear regression of $\Delta \mathrm{Chl}$ on $F_{\mathrm{C}}$ (one example shown in Fig. 9). The parameter $\gamma_{0}$ is the $y$-axis intercept $\left(\Delta C h l\right.$ at $\left.F_{C}=0\right)$ and $\gamma_{1}$ is the slope of the line segment between $F_{\mathrm{C}}=0$ and the breakpoint value of $F_{\mathrm{C}}$. Each bar represents the median of the Monte Carlo ensemble of parameter estimates, and the number is the frequency of occurrence of negative values in the ensemble. Bars shaded in black indicate a significant difference from zero $(95 \% \mathrm{CI}$, based on percentiles of the ensemble, did not include zero). Negative $\gamma_{0}$ indicates a lakewide post-invasion reduction in chlorophyll independent of the spatial distribution of Dreissena filter feeding. Negative $\gamma_{1}$ indicates a post-invasion reduction in chlorophyll that is spatially associated with Dreissena filter-feeding intensity, $F_{\mathrm{C}}$.

stratification, and the winter-spring bloom may not occur at all.

While the disappearance of the winter-spring phytoplankton bloom after the dreissenid invasion has been shown previously for the southern basin of Lake Michigan (Fahnenstiel et al., 2010b; Kerfoot et al., 2010; Vanderploeg et al., 2010; Yousef et al., 2014), our refined maps of dreissenid biomass spatial distribution, covering 
all of Lake Michigan, show the spatial coherence of the mussel filter-feeding intensity with reduced chlorophyll concentrations. There was a significant reduction in chlorophyll caused by the local impact of dreissenid filter feeding (Fig. 10, $\gamma_{1}<0$ ) in winter and spring, when Lake Michigan is often well mixed to the bottom. The local filter-feeding impact saturated when the fraction of the water column cleared per day by Dreissena was near the benchmark spring phytoplankton growth rate of 0.06 day $^{-1}$. In addition to the local filter-feeding impact, a post-invasion reduction in chlorophyll occurred lakewide, including locations that were not locally affected by dreissenid grazing (Fig. 10, $\gamma_{0}<0$ ).

The significant positive $\gamma_{1}$ value that occurred in June was surprising because it might be interpreted to suggest greater chlorophyll concentration at locations where dreissenid filter-feeding intensity was greatest. Direct, local effects of dreissenid filter feeding would not be expected in June when stratification cuts off benthic filter feeders from surface chlorophyll. One possible explanation for the higher June chlorophyll concentration in locations affected by dreissenid filter feeding is an indirect effect through altered nutrient cycling; uptake of available phosphorus may have been delayed by the suppression of the winter-spring bloom so that available phosphorus in June was greater post- than pre-invasion. Additional data would be needed to test this hypothesis. June was also unique for having the largest post-invasion reduction in chlorophyll (Fig. 10, top) that was not related to local filter-feeding impacts (negative $\gamma_{0}$ value). The large lakewide reduction in June chlorophyll after the invasion is likely to be a cumulative effect of the suppression of the winter-spring bloom over the preceding months.

The mid-lake reef provided an interesting test of the ability of the geostatistical model to predict the occurrence of Dreissena at locations where observations were not available in the Ponar survey data set. The mid-lake reef has a substratum consisting of carbonate rock and separates the southern and central regions of Lake Michigan (Fig. 3). This reef area could not be sampled in the surveys owing to the inability of the Ponar grab to collect a sample from a hard substratum. The geostatistical model predicted the occurrence of Dreissena on the mid-lake reef complex based on the suitable depth habitat of the reef (depths of 40-100 m). Surveys and images taken with a remotely operated underwater vehicle (ROV) indicated that D. r. bugensis was scarce on the reef complex in 2002 but had densely colonised it by 2006 (Houghton, Paddock \& Janssen, 2014), which is consistent with the spatial distributions shown in Fig. 4.
Given the rapid expansion of D. r. bugensis over the 15 -year sampling period, and the decline in phytoplankton, it is interesting to consider whether there is any indication that this species has approached a limited carrying capacity in Lake Michigan over the most recent period (2005-2010). Note that D. r. bugensis first invaded Lake Michigan in the northern region (first found in 1997) and subsequently spread southwards (Nalepa et al., 2001, 2009). In the <30-m depth interval, biomass converged towards $10 \mathrm{~g} \mathrm{AFDM} \mathrm{m}^{-2}$, decreasing in the northern, increasing in the southern and remaining constant in the central region. In a similar manner, biomass converged towards $20-30 \mathrm{~g}^{\mathrm{AFDM} \mathrm{m}}{ }^{-2}$ within the 30- to 50- and 50- to 90-m depth intervals. The observation that biomass declined or remained constant in some northern regions, while biomass increased in the south but had not yet reached the peak values observed in the north, would be consistent with carrying capacities of c. $10 \mathrm{~g} \mathrm{AFDM} \mathrm{m}^{-2}$ in the $<30-\mathrm{m}$ depth range and 20 $30 \mathrm{~g} \mathrm{AFDM} \mathrm{m}^{-2}$ in the $30-$ to $90-\mathrm{m}$ depth range. Since biomass was still increasing in the $>90-\mathrm{m}$ depth range lakewide, and this range comprises a large portion of total lake area $(43 \%)$, further monitoring will be needed to reveal the ultimate carrying capacity for Dreissena in Lake Michigan.

We expect spatial patterns in Dreissena biomass in Lake Michigan to continue to shift in relation to variable population growth and responses to environmental conditions (self-induced or otherwise). As illustrated, biomass can be broadly different depending on lake region and depth. Since dreissenids have such profound impacts on water quality, nutrient and energy cycling, and the abundance of other species, not only in Lake Michigan (Fahnenstiel et al., 2010a) but in other bodies of water (Higgins \& Vander Zanden, 2010), detailed distribution maps based on benthic surveys and the geostatistical modelling approach outlined here provide a valuable tool for assessing and interpreting further impacts at both whole lake and regional scales.

\section{Acknowledgments}

M. D. Rowe received funding through the National Research Council Research Associate programme. Additional support was provided by NOAA GLERL, the University of Michigan Water Center and the Cooperative Institute for Limnology and Ecosystems Research (CILER). D. Scavia, University of Michigan, is gratefully acknowledged for comments on the manuscript. This is GLERL Contribution No. 1771. 


\section{References}

Auer M., Tomlinson L., Higgins S., Malkin S., Howell E. \& Bootsma H. (2010) Great Lakes Cladophora in the 21st century: same algae-different ecosystem. Journal of Great Lakes Research, 36, 248-255.

Auer M.T., Auer N.A., Urban N.R. \& Auer T. (2013) Distribution of the amphipod Diporeia in lake superior: the ring of fire. Journal of Great Lakes Research, 39, 33-46.

Beletsky D. \& Schwab D. (2001) Modeling circulation and thermal structure in Lake Michigan: annual cycle and interannual variability. Journal of Geophysical Research, 106, 19745-19771.

Beletsky D., Schwab D. \& McCormick M. (2006) Modeling the 1998-2003 summer circulation and thermal structure in Lake Michigan. Journal of Geophysical Research, 111, 118.

Benson A.J. (2014) Chronological history of zebra and quagga mussels (Dreissenidae) in North America, 19882010. In: Quagga and Zebra Mussels: Biology, Impacts, and Control. (Eds T.F. Nalepa \& D.W. Schloesser), pp. 9-29. CRC Press, Boca Raton.

Box G.E. \& Cox D.R. (1964) An analysis of transformations. Journal of the Royal Statistical Society. Series B (Methodological), 26(2), 211-252.

Brown J.E. \& Stepien C.A. (2010) Population genetic history of the dreissenid mussel invasions: expansion patterns across North America. Biological invasions, 12, 3687-3710.

Chiles J.P. \& Delfiner P. (2009) Geostatistics: Modeling Spatial Uncertainty. John Wiley \& Sons, New York.

Connelly N.A., O'Neill C.R. Jr, Knuth B.A. \& Brown T.L. (2007) Economic impacts of zebra mussels on drinking water treatment and electric power generation facilities. Environmental Management, 40, 105-112.

Coordinating Committee on Great Lakes Basic Hydraulic and Hydrologic Data. (1977) Coordinated Great Lakes Physical Data. Chicago, IL and Cornwall, ON. pp. 9.

Diggle P. \& Ribeiro P. Jr (2007) Model-based Geostatistics. Springer, New York.

Fahnenstiel G., Nalepa T., Pothoven S., Carrick H. \& Scavia D. (2010a) Lake Michigan lower food web: long-term observations and Dreissena impact. Journal of Great Lakes Research, 36, 1-4.

Fahnenstiel G.L., Pothoven S., Vanderploeg H., Klarer D., Nalepa T. \& Scavia D. (2010b) Recent changes in primary production and phytoplankton in the offshore region of southeastern Lake Michigan. Journal of Great Lakes Research, 36, 20-29.

Fahnenstiel G.L. \& Scavia D. (1987) Dynamics of Lake Michigan phytoplankton: recent changes in surface and deep communities. Canadian Journal of Fisheries and Aquatic Sciences, 44, 509-514.

Fahnenstiel G.L., Stone R.A., McCormick M.J., Schelske C.L. \& Lohrenz S.E. (2000) Spring isothermal mixing in the Great Lakes: evidence of nutrient limitation and nutrient- light interactions in a suboptimal light environment. Canadian Journal of Fisheries and Aquatic Sciences, 57, 19011910.

Hecky R., Smith R.E., Barton D., Guildford S., Taylor W., Charlton M. et al. (2004) The nearshore phosphorus shunt: a consequence of ecosystem engineering by dreissenids in the Laurentian Great Lakes. Canadian Journal of Fisheries and Aquatic Sciences, 61, 1285-1293.

Higgins S.N. \& Vander Zanden M.J. (2010) What a difference a species makes: a meta-analysis of dreissenid mussel impacts on freshwater ecosystems. Ecological Monographs, 80, 179-196.

Houghton J.S., Paddock R. \& Janssen J. (2014) Invasion of quagga mussels (Dreissena rostriformis bugensis) to the mid-lake reef complex in Lake Michigan: a photographic montage. In: Quagga and Zebra Mussels: Biology, Impacts, and Control. (Eds T.F. Nalepa \& D.W. Schloesser), pp. 6570. CRC Press, Boca Raton.

Jardim E. \& Ribeiro P.J. Jr (2007) Geostatistical assessment of sampling designs for Portuguese bottom trawl surveys. Fisheries Research, 85, 239-247.

Jardim E. \& Ribeiro P.J. Jr (2008) Geostatistical tools for assessing sampling designs applied to a Portuguese bottom trawl survey field experience. Scientia Marina, 72, 623-630.

Karatayev A.Y., Burlakova L.E., Mastitsky S.E., Padilla D.K. \& Mills E.L. (2011) Contrasting rates of spread of two congeners, Dreissena polymorpha and Dreissena rostriformis bugensis, at different spatial scales. Journal of Shellfish Research, 30, 923-931.

Karatayev A.Y., Burlakova L.E. \& Padilla D.K. (2002) Impacts of zebra mussels on aquatic communities and their roles as ecosystem engineers. In: Invasive Aquatic Species of Europe. Distribution, Impacts and Management. (Eds E. Leppa-koski, S. Gollash, and S. Olenin), pp. 433-446. Kluwer Academic Publishers, Dordrecht, The Netherlands.

Karatayev A.Y., Burlakova L.E. \& Padilla D.K. (2014) Zebra versus quagga mussels: a review of their spread, population dynamics, and ecosystem impacts. Hydrobiologia, 746 (1), 1-16.

Kerfoot W.C., Budd J.W., Green S.A., Cotner J.B., Biddanda B.A., Schwab D.J. et al. (2008) Doughnut in the desert: late-winter production pulse in southern Lake Michigan. Limnology and Oceanography, 53, 589.

Kerfoot W.C., Yousef F., Green S.A., Budd J.W., Schwab D.J. \& Vanderploeg H.A. (2010) Approaching storm: disappearing winter bloom in Lake Michigan. Journal of Great Lakes Research, 36, 30-41.

Lesht B.M., Barbiero R.P. \& Warren G.J. (2013) A band-ratio algorithm for retrieving open-lake chlorophyll values from satellite observations of the Great Lakes. Journal of Great Lakes Research, 39, 138-152.

Madenjian C.P., Pothoven S.A., Dettmers J.M. \& Holuszko J.D. (2006) Changes in seasonal energy dynamics of alewife (Alosa pseudoharengus) in Lake Michigan after 
invasion of dreissenid mussels. Canadian Journal of Fisheries and Aquatic Sciences, 63, 891-902.

Muggeo V.M.R. (2003) Estimating regression models with unknown break-points. Statistics in medicine, 22, 30553071.

Muggeo V.M.R. (2008) Segmented: an R package to fit regression models with broken-line relationships. $R$ News, 8, 20-25.

Nalepa T.F., Cavaletto J.F., Ford M., Gordon W.M. \& Wimmer M. (1993) Seasonal and annual variation in weight and biochemical content of the zebra mussel, Dreissena polymorpha, in Lake St. Clair. Journal of Great Lakes Research, 19, 541-552.

Nalepa T.F., Fanslow D.L. \& Lang G.A. (2009) Transformation of the offshore benthic community in Lake Michigan: recent shift from the native amphipod Diporeia spp. to the invasive mussel Dreissena rostriformis bugensis. Freshwater Biology, 54, 466-479.

Nalepa T.F., Fanslow D.L., Lang G.A., Lamarand D.B., Cummins L.G. \& Carter G.S. (2008) Abundances of the amphipod Diporeia spp. and the mussels Dreissena polymorpha and Dreissena rostriformis bugensis in Lake Michigan in 1994-1995, 2000, and 2005. NOAA Technical Memorandum GLERL-144, Ann Arbor, Michigan, USA, p. 25, URL: http:/ /www.glerl.noaa.gov/ftp/publications/tech_reports / glerl-144/tm-144.pdf.

Nalepa T.F., Fanslow D.L., Mabrey K., Lang G.A. \& Rowe M.D. (2014) Lake-wide benthic surveys in Lake Michigan in 1994-1995, 2005, 2005, and 2010: Abundances of the amphipod Diporeia spp., and abundances and biomass of mussels Dreissena polymorpha and Dreissena rostriformis bugensis. NOAA Technical Memorandum GLERL-164, Ann Arbor, Michigan, USA, p. 25, URL: http://www.glerl.noaa.gov/ftp/publications/tech_reports/glerl-164/tm164.pdf.

Nalepa T.F., Fanslow D.L. \& Pothoven S.A. (2010) Recent changes in density, biomass, recruitment, size structure, and nutritional state of Dreissena populations in southern Lake Michigan. Journal of Great Lakes Research, 36, 5-19.

Nalepa T.F., Schloesser D.W., Pothoven S.A., Hondorp D.W., Fanslow D.L., Tuchman M.L. et al. (2001) First finding of the amphipod Echinogammarus ischnus and the mussel Dreissena bugensis in Lake Michigan. Journal of Great Lakes Research, 27, 384-391.

Obenour D.R., Gronewold A.D., Stow C.A. \& Scavia D. (2014) Using a Bayesian hierarchical model to improve Lake Erie cyanobacteria bloom forecasts. Water Resources Research, 50, 7847-7860.

Obenour D.R., Scavia D., Rabalais N.N., Turner R.E. \& Michalak A.M. (2013) Retrospective analysis of midsummer hypoxic area and volume in the northern Gulf of Mexico, 1985-2011. Environmental Science $\mathcal{E}$ Technology, 47, 9808-9815.

Pothoven S.A., Fahnenstiel G.L. \& Vanderploeg H.A. (2010) Temporal trends in Mysis relicta abundance, production, and life-history characteristics in southeastern Lake Michigan. Journal of Great Lakes Research, 36, 60-64.

R Core Team. (2012) R: A Language and Environment for Statistical Computing. $\mathrm{R}$ Foundation for Statistical Computing, Vienna, Austria. ISBN 3-900051-07-0. Available at: http://www.R-project.org/.

Ribeiro P.J.. Jr, Christensen O.F. \& Diggle P.J. (2003) geoR and geoRglm: software for model-based geostatistics. In: Proceedings of the 3rd International Workshop on Distributed Statistical Computing (DSC 2003), Vienna, Austria. (Eds. K. Hornik, L. Friedrich \& Z. Achim), pp. 1-16. R project, http://www.r-project.org/conferences/DSC-2003/Procee dings/.

Ribeiro P.J. Jr \& Diggle P.J. (2001) geoR: a package for geostatistical analysis. R-NEWS, 1, 15-18.

Schummer M.L., Petrie S.A. \& Bailey R.C. (2008) Dietary overlap of sympatric diving ducks during winter on northeastern Lake Ontario. The Auk, 125, 425-433.

Schwarz G. (1978) Estimating the dimension of a model. The Annals of Statistics, 6, 461-464.

Shuchman R.A., Leshkevich G., Sayers M.J., Johengen T.H., Brooks C.N. \& Pozdnyakov D. (2013) An algorithm to retrieve chlorophyll, dissolved organic carbon, and suspended minerals from Great Lakes satellite data. Journal of Great Lakes Research, 39, 14-33.

Sibson R. (1981) A brief description of natural neighbour interpolation. In: Interpreting Multivariate Data. (Ed Barnett V.), pp. 21-36. Wiley, New York.

Siegel D., Doney S. \& Yoder J. (2002) The North Atlantic spring phytoplankton bloom and Sverdrup's critical depth hypothesis. Science, 296, 730-733.

Steffen M.M., Belisle B.S., Watson S.B., Boyer G.L. \& Wilhelm S.W. (2014) Status, causes and controls of cyanobacterial blooms in Lake Erie. Journal of Great Lakes Research, 40, 215-225.

Sverdrup H. (1953) On conditions for the vernal blooming of phytoplankton. Journal du Conseil, 18, 287-295.

Vanderploeg H.A., Liebig J.R., Carmichael W.W., Agy M.A., Johengen T.H., Fahnenstiel G.L. et al. (2001) Zebra mussel (Dreissena polymorpha) selective filtration promoted toxic Microcystis blooms in Saginaw Bay (Lake Huron) and Lake Erie. Canadian Journal of Fisheries and Aquatic Sciences, 58, 1208-1221.

Vanderploeg H.A., Liebig J.R., Nalepa T.F., Fahnenstiel G.L. \& Pothoven S.A. (2010) Dreissena and the disappearance of the spring phytoplankton bloom in Lake Michigan. Journal of Great Lakes Research, 36, 50-59.

Vanderploeg H.A., Nalepa T.F., Jude D.J., Mills E.L., Holeck K.T., Liebig J.R. et al. (2002) Dispersal and emerging ecological impacts of Ponto-Caspian species in the Laurentian Great Lakes. Canadian Journal of Fisheries and Aquatic Sciences, 59, 1209-1228.

Wang J., Bai X., Hu H., Clites A., Colton M. \& Lofgren B. (2012) Temporal and spatial variability of great lakes ice cover, 1973-2010. Journal of Climate, 25, 1318-1329.

(C) 2015 John Wiley \& Sons Ltd, Freshwater Biology, 60, 2270-2285 
Yousef F., Kerfoot W.C., Shuchman R. \& Fahnenstiel G. (2014) Bio-optical properties and primary production of Lake Michigan: insights from 13-years of SeaWiFS imagery. Journal of Great Lakes Research, 40, 317-324.

Zhou Y., Obenour D.R., Scavia D., Johengen T.H. \& Michalak A.M. (2013) Spatial and temporal trends in Lake Erie hypoxia, 1987-2007. Environmental Science E Technology, 47, 899-905.

Zimmerman D.L. (2010) Likelihood-Based Methods. In: Handbook of Spatial Statistics. (Eds A.E. Gelfand, P.J.Diggle, M. Fuentes \& P. Guttorp), pp. 45-56. CRC Press, Boca Raton, FL.

\section{Supporting Information}

Additional Supporting Information may be found in the online version of this article:
Data S1. Lake Michigan Dreissena biomass values from the geostatistical model on the $2-\mathrm{km}$ prediction grid are provided in the text files 'Rowe_etal_LakeMichiganDreissenaBiomass_X.txt', where $X$ is the year (1994-95, 2000, 2005, 2010), and the Dreissena biomass observed values are provided in the file 'Nalepa_DreissenidLakeMichigan.txt'.

(Manuscript accepted 6 July 2015) 